\title{
Luminescence Tuning of MEH-PPV for Organic Electronic Applications
}

\author{
B.A. PAEZ-Sierra ${ }^{a, *}$ AND D.M. MARUlandA ${ }^{b}$ \\ ${ }^{a}$ Departamento de Física, Grupo de Docencia e Investigación en Física, Universidad Militar Nueva Granada, \\ Carrera 11 No. 101-80; Carrera 30 No. 45-03, Bogotá, Colombia \\ ${ }^{b}$ Grupo de Investigación REM-Research in Energy and Materials, Universidad Antonio Nariño, \\ Bogotá, Colombia \\ (Received November \%, 2015) \\ In this report, a doped semiconducting ink consisting of a blended poly [2-methoxy-5-(2'-ethyl-hexyloxy)- \\ 1,4-phenylene vinylene] (MEH-PPV) with aluminium-tris (8-hydroxychinolin) ( $\mathrm{Alq}_{3}$ ) and diluted in toluene is \\ formulated. The intentional doping with the electron transport nanoparticle Alq $\mathrm{A}_{3}$ results in an additional band \\ gap state of the hole transport MEH-PPV polymer and reduction of the switch on voltage of the organic LED \\ display. Doping is probed at room temperature with photoluminescence spectroscopy. Photoluminescence results \\ revealed that as the $\mathrm{Alq}_{3}$ content increases in blends, characteristic peaks of intensities of MEH-PPV are broadened \\ and reduced. In addition, the emission for $\mathrm{Alq}_{3}$ concentrations between $30 \%$ and $60 \%$ are featured by a band at \\ $565 \mathrm{~nm}(2.19 \mathrm{eV})$ for the lower concentration and consistently blue shifted to $530 \mathrm{~nm}(2.33 \mathrm{eV})$ for the higher \\ concentration. This new band at $565 \mathrm{~nm}(2.19 \mathrm{eV})$ neither belongs to pure MEH-PPV nor to Alq ${ }_{3}$ and evidences \\ charge transfer from the lowest unoccupied molecular orbital of the Alq $\mathrm{A}_{3}$ to the highest occupied molecular orbital \\ of the MEH-PPV.
}

DOI: 10.12693/APhysPolA.129.1187

PACS/topics: 72.80.Le, 78.55.Hx

\section{Introduction}

Organic molecules with $\pi$-conjugated structures provide a variety of new materials with metallic and semiconducting properties, attractive for fundamental investigations, engineering applications [1-4], and as a potential bench mark in nanomedicine or life science products at lab-on-a-chip devices [5]. Although several organic based devices, i.e., organic light emitting diodes (OLEDs) and organic photovoltaics (OPVs), have matured for commercial applications, still a long-standing challenge in molecular electronics relays on doping of organic semiconductors [6-10]. Therefore, nanoelectronic engineering by doping of semiconducting materials results from tuned molecules for well-targeted applications. Particularly, OLEDs constitute a novel emission light technology and OPVs is a promising area in the field of green energy generation. Both OLEDs and OPVs structures consist of a stack of organic semiconducting layers sandwiched between a transparent conducting anode and metallic cathode [11-13].

Among the key features of doping organic semiconductors are: (i) precise adjustment of the position of the Fermi level relative to the semiconductor transport levels, (ii) control of energy barriers for charge injection/extraction, and hence (iii) reduction of ohmic losses in transport layers due to increased

\footnotetext{
* corresponding author; e-mail: beynor.paez@unimilitar.edu.co
}

conductivity [10,14-17]. In a previous work, Ahmad et al. found that blending MEH-PPV with $\mathrm{Alq}_{3}$ in chloroform leads to minor changes in the photoluminescence and favors the photodetection properties [18]. Similarly, Yakuphanoglu et al. observed photovoltaic effects in blends of MEH-PPV with PCBM [19]. In our case, the blending process was carried out in toluene and the MEH-PPV:Alq ${ }_{3}$ layers revealed dramatic changes on the photoluminescence spectrum, suitable for OLED devices. Therefore, it is evidenced a charge transfer from the lowest unoccupied molecular orbital (LUMO) of the $\mathrm{Alq}_{3}$ to highest occupied molecular orbital (HOMO) of the MEH-PPV.

In this investigation, UV-vis absorption and photoluminescence (PL) spectroscopy were used to monitor the molecular doping of MEH-PPV with $\mathrm{Alq}_{3}$. Optical probes are known as non-invasive methods and give direct information on electronic states.

\section{Experimental}

The organic molecules MEH-PPV and $\mathrm{Alq}_{3}$ with a purity $>99 \%$ were purchased from Sigma Aldrich and their chemical structures are shown in Fig. 1a and b. The formulated ink (Fig. 1c) consisted of a blended MEH-PPV with $\mathrm{Alq}_{3}$ diluted in toluene at $1 \%$ by weight. Previous to the blending process, MEH-PPV and $\mathrm{Alq}_{3}$-based inks were bottled separately in an argon atmosphere and kept stirring on the hot plate at $65^{\circ} \mathrm{C}$ and at $95^{\circ} \mathrm{C}$, respectively, during $24 \mathrm{~h}$. After that, the solutions were blended at $65^{\circ} \mathrm{C}$ during one hour. Concentrations of $\mathrm{Alq}_{3}$ in MEH-PPV were set by weight at $10 \%, 15 \%$, 
$20 \%, 30 \%, 40 \%, 45 \%, 60 \%$, and $100 \%$. In order to test the homogeneity of the $\mathrm{Alq}_{3}$, separate vessels were centrifuged at $15000 \mathrm{~g}$, revealing partial separation of the $\mathrm{Alq}_{3}$ molecule and the solvent. The pristine and doped MEH-PPV solutions were spin-coated on quartz substrates to form $50 \mathrm{~nm}$ thick films, which were optically analyzed by photoluminescence. The optical setup consisted of a thermoelectrically cooled (TEC) USB-based photoluminescence spectrometer designed at QUBITeXp International Trade S.A.S. Colombia [19, 20]. The setup consists of a $405 \mathrm{~nm}$ solid-state laser source focused on the samples with a $20 \times$ objective. Then, the backscattered light passes through a long pass filter to block the laser. Finally, the filtered signal is addressed with concave optical mirrors to a multimodal $1000 \mu \mathrm{m}$ core optical fiber. Inside the spectrometer, the incoming light shines onto a holographic grating of 1200 lines/mm. Finally, the dispersed signal is recorded in a TEC linear CCD array and transmitted via USB to the computer. For the UV-vis measurements, the same setup was used and samples were illuminated in transmission configuration with a deuterium-tungsten lamp.

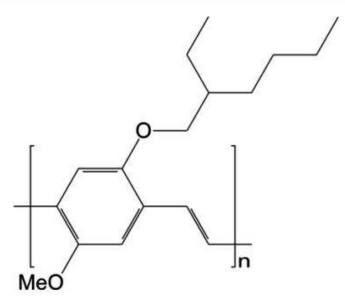

(a)

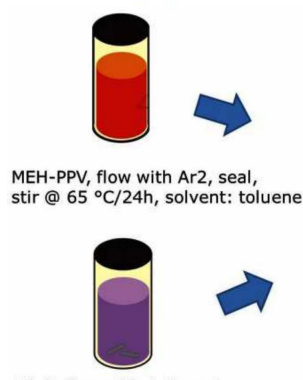

Alq3, flow with Ar2, seal, stir @ $95^{\circ} \mathrm{C} / 24 \mathrm{~h}$, solvent: toluene.

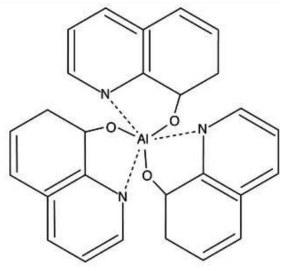

(b)

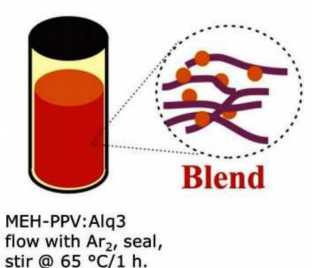

(c)
Fig. 1. Diagrams of molecular structures and semiconducting ink. (a) Semiconducting polymer MEH-PPV, (b) low molecular weight organic semiconductor $\mathrm{Alq}_{3}$, and (c) scheme of the semiconducting-ink formulation.

Bendable OLEDs were produced to test the ink formulations. The OLED structure accomplishes a bendable and transparent substrate of polyethylene terephthalate (PET) with patterned ITO contacts. Onto this substrate the doped ink was spin coated to produce a $50 \mathrm{~nm}$ thick film. The circuit was completed by thermal evaporation of $100 \mathrm{~nm}$ aluminum film in high vacuum conditions through a shadow mask and encapsulated with a moisture-resistant film (Fig. 2). Finally, the device performance was optoelectronically tested.
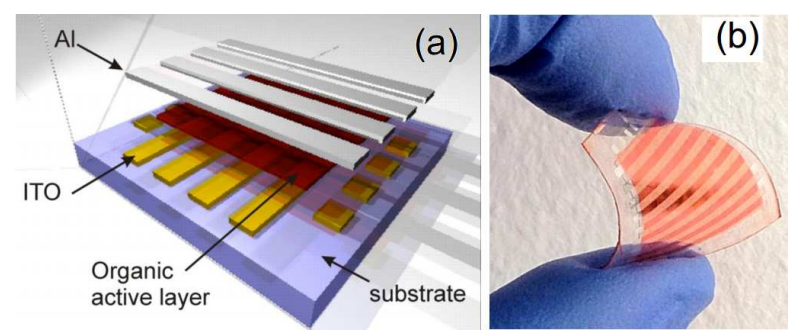

Fig. 2. Organic light emitting diode (OLED): (a) interlayer configuration and (b) picture of the bendable OLED display.

\section{Results and discussion}

Absorption spectra of MEH-PPV:Alq ${ }_{3}$ at different concentrations were carried out and are shown in Fig. 3. All spectra are normalized to the intensity at $263 \mathrm{~nm}$. Spectra for all concentrations of $\mathrm{Alq}_{3}$ revealed a linear dependence between spectra of both molecules MEH-PPV and $\mathrm{Alq}_{3}$. This suggests that $\mathrm{Alq}_{3}$ is incorporated into the MEH-PPV matrix without modifying the chemical structure of the semiconducting polymer. Upon inclusion of $\mathrm{Alq}_{3}$ in MEH-PPV, a light broadening of the UV-vis spectrum in comparison with pristine MEH-PPV films is observed. Therefore, it is likely that minor molecular orbital hybridization between the HOMO of MEH-PPV and the LUMO of $\mathrm{Alq}_{3}$ is achieved. Thus, a ground state charge-transfer complex is formed, in which occupation of the available states results in a low doping efficiency [10].

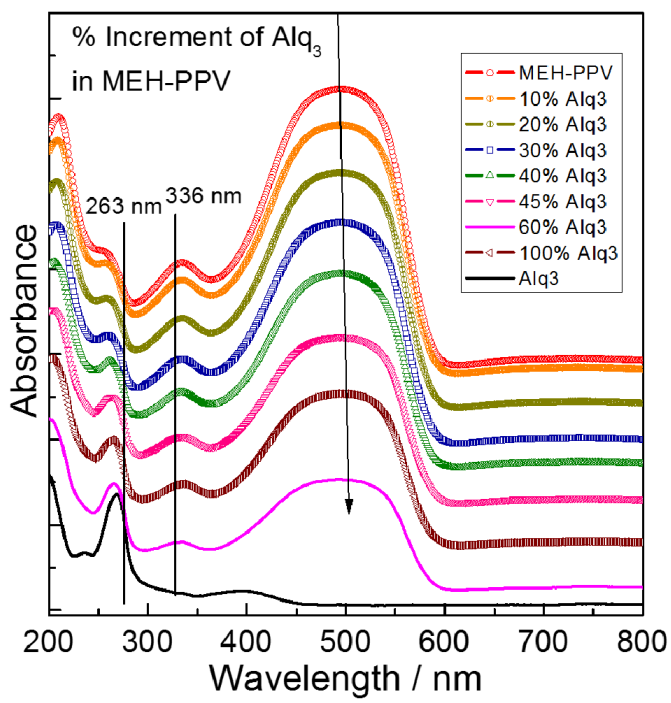

Fig. 3. Absorption spectra of $\mathrm{MEH}-\mathrm{PPV}: \mathrm{Alq}_{3}$ thin films with different concentration of $\mathrm{Alq}_{3}$.

The room temperature normalized PL spectra for various concentrations of $\mathrm{Alq}_{3}$ are depicted in Fig. 4, where the incremental participation of $\mathrm{Alq}_{3}$ in MEH-PPV is presented. Pure MEH-PPV film is characterized by two main peaks, located at $585 \mathrm{~nm}$ and $631 \mathrm{~nm}$. The emission of MEH-PPV for $15 \%$ or lower $\mathrm{Alq}_{3}$ doping remains unmodified. In contrast, for $\mathrm{Alq}_{3}$ doping above 30\%, 


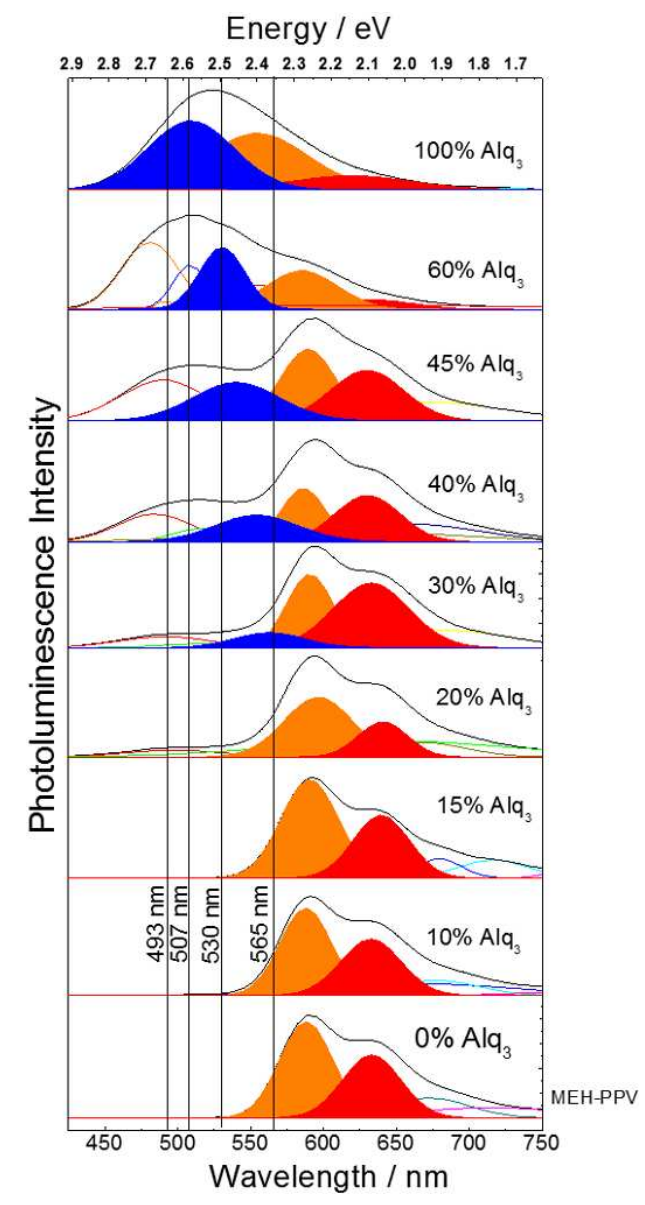

Fig. 4. Photoluminescence measurements at room temperature of MEH-PPV:Alq ${ }_{3}$.

a blue shift emission is presented, while for $40 \% \mathrm{Alq}_{3}$ concentration, the maximum emission returns to the observed in $10 \%$ and $20 \%$ concentration. It is likely that the quenching of trap states occur for $\mathrm{Alq}_{3}$ concentrations below 40\%, while for higher densities of $\mathrm{Alq}_{3}$ in the MEH-PPV polymer matrix, trap passivation is completed and then PL emission is dominated from $\mathrm{Alq}_{3}$ molecules. For $\mathrm{Alq}_{3}$ concentrations higher than 30\%, charge injection is favored from the ITO anode to the $\mathrm{Alq}_{3} \mathrm{HOMO}$, thus charge carriers have to overcome a higher barrier. The same behavior has been reported by Krautz et al. and Kumar et al. [21, 22].

At $20 \% \mathrm{Alq}_{3}$ concentration, bands at $493 \mathrm{~nm}$ and $530 \mathrm{~nm}$ are registered. Light emission comes from the superposition of $\mathrm{MEH}-\mathrm{PPV}$ and $\mathrm{Alq}_{3}$ emissions. The composed PL is assigned to independent emission centers without formation of new molecular complexes, which is in agreement with the UV-vis spectra reported in Fig. 3. One reason for the independent emission is the low homogeneity of the $\mathrm{Alq}_{3}$ molecule in the solvent.

Bendable OLED devices were developed with the formulated ink. A scheme of the OLED band diagram aligment of ITO/MEH-PPV:Alq $3 / \mathrm{Al}$ is depicted in Fig. 5. It was found that inclusion of $\mathrm{Alq}_{3}$ nanoparticles to the

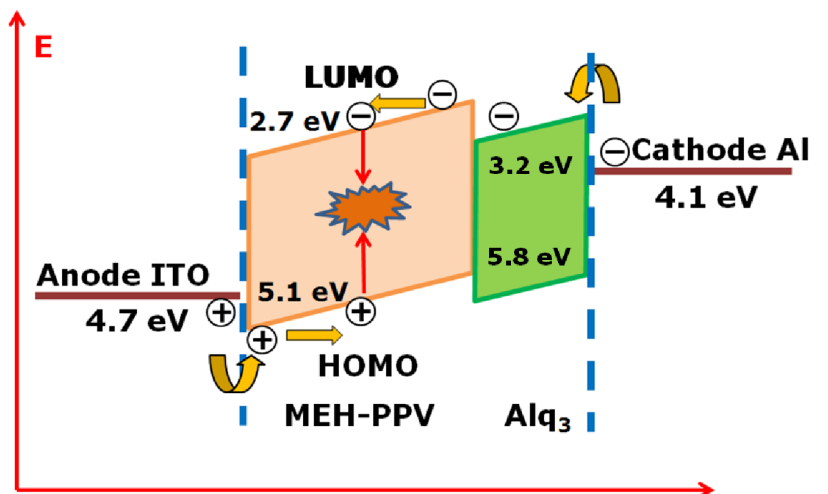

Fig. 5. Energy diagram of the doped OLED.

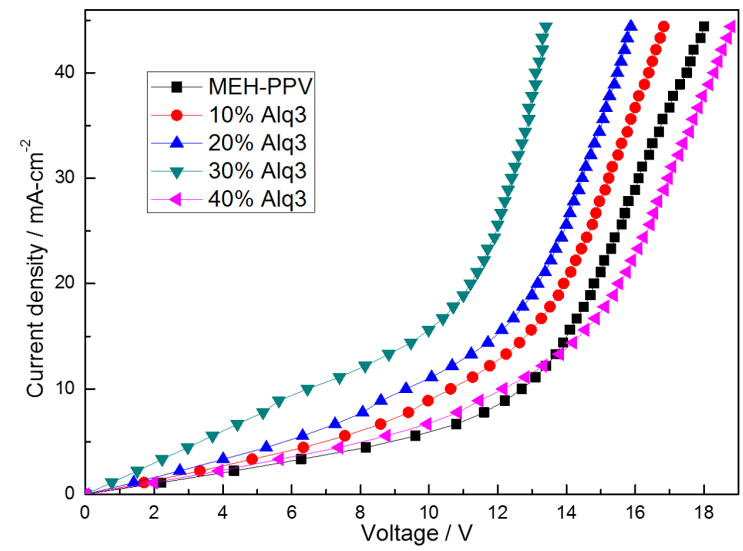

Fig. 6. $J-V$ characteristics with $\%$ increments of $\mathrm{Alq}_{3}$ in MEH-PPV OLED Schottky diodes.

MEH-PPV matrix reduces the energy barrier of injected electrons from the Al cathode $[18,23]$. The current density versus voltage characteristic of the devices with MEH-PPV at different concentrations of $\mathrm{Alq}_{3}$ (10\%, 20\%, $30 \%$, and $40 \%)$ is depicted in Fig. $6(J-V)$. For Alq 3 concentrations among $10 \%$ and $30 \%$, the switch on voltage of pixels is reduced from approximately $16 \mathrm{~V}$ to $8 \mathrm{~V}$, while for devices with $40 \% \mathrm{Alq}_{3}$, the current density increases accompanied with an increment of the switch on voltage; this implies that there is always an injection in the system load, independent of the degree of doping, and as a consequence a passivation of the trap levels of MEH-PPV shown by the Alq ${ }_{3}$ occurs. However, for $\mathrm{Alq}_{3}$ concentrations over $40 \%$, an increase of the diode potential barrier is presented, indicating that traps are found in deeper energy levels and close to the anode work function.

In Fig. 6, it is observed that there is an increase in the current intensity in all samples when the percent of $\mathrm{Alq}_{3}$ increases. The higher $J / V$ ratio for samples made with $10 \% \mathrm{Alq}_{3}$ shows that these films have a lower ohmic resistance, which is probably due to the high density of pinholes in thinner organic films. Pinholes provide the path of parasitic anode--cathode currents via direct contact, which contributes to the ohmic component of net current. The same behavior has been reported in previous works based on OLEDs [24]. At the same time, 
significant electron trap states rather than hole traps are induced. In this case, electron-hole recombination will mostly take place near the electron-transporting layer. Thus, solution processing may lead to a reduction in the electron transport mobility as a result of electron charge traps $[21,25-28]$.

\section{Conclusions}

We investigated a doped semiconducting ink consisting of a blended MEH-PPV with $\mathrm{Alq}_{3}$ and diluted in toluene. The MEH-PPV:Alq 3 revealed dramatic changes on the PL. PL shows that for dopings equal or lower than $15 \%$ concentrations the MEH-PPV profile remains unmodified. In contrast, PL spectrum of the MEHPPV:Alq ${ }_{3}$ formulation with a $30 \%$ doping is characterized by a band at $565 \mathrm{~nm}(2.19 \mathrm{eV})$ and is continuously blueshifted to $530 \mathrm{~nm}(2.33 \mathrm{eV})$ for higher $\mathrm{Alq}_{3}$ concentrations. Photoluminescence emission of MEH-PPV:Alq is composed of independent emission of each molecule. For concentrations above $15 \%$ a significant effect of $\mathrm{Alq}_{3}$ in the MEH-PPV matrix is observed. Therefore, the ink formulation $\mathrm{MEH}-\mathrm{PPV}: \mathrm{Alq}_{3}$ prepared at $65^{\circ} \mathrm{C}$ lacks of formation of molecular complexes or hybridization between the HOMO of MEH-PPV and the LUMO of $\mathrm{Alq}_{3}$. An explanation of the individual contribution to the $\mathrm{PL}$ of $\mathrm{Alq}_{3}$ and MEH-PPV is assigned to low homogeneity of $\mathrm{Alq}_{3}$ in the solvent, which is confirmed through the UV-vis spectra.

Despite at higher concentrations of $30 \% \mathrm{Alq}_{3}$ the PL is dramatically modified, the current-voltage characteristics turn into lower current densities and higher switch-on voltages. UV-vis measurements assessed a weak molecular doping, since only a minor broadening of the spectra of MEH-PPV:Alq 3 was observed. Therefore, appearance of a ground-state charge-transfer complex is formed, in which occupation of the available states results in a weak doping mechanism. The MEH-PPV:Alq ${ }_{3}$ blends are a promissory alternative to minimize the interchain interaction during the film processing. In addition, doping increases the effective conjugation length of MEH-PPV and reduces the switch on voltage of OLEDs.

\section{Acknowledgments}

This work was supported by Universidad Militar Nueva Granada (Bogotá, Colombia) within the research line of the physics department on Nanophotonics and Sensorics. Paez and Marulanda are indebted to QUBITeXp International Trade S.A.S., Colombia.

\section{References}

[1] G. Salvan, B.A. Paez, D.R.T. Zahn, L. Gisslen, R. Scholz, in: Physical and Chemical Aspects of Organic Electronics: From Fundamentals to Functioning Devices: Structural and Electronic Properties of OFETs, Ed. C. Wöll, Wiley-VCH, Weinheim 2009, Ch. 13.

[2] H. Klauk, Organic Electronics II: More Materials and Applications, Wiley-VCH, Weinheim 2012.

[3] J. Roncali, P. Leriche, P. Blanchard, Adv. Mater. 26, 3821 (2014).
[4] S. Xue, X. Qiu, L. Yao, L. Wang, M. Yao, C. Gu, Y. Wang, Z. Xie, H. Wu, Org. Electron. 27, 35 (2015).

[5] O. Pabst, J. Perelaer, E. Beckert, U.S. Schubert, R. Eberhardt, A. Tünnermann, Org. Electron. 14 3423 (2013)

[6] H. Shirakawa, E.J. Louis, A.G. Macdiarmid, C.K. Chiang, A.J. Heeger, J. Chem. Soc. Chem. Commun. 1977, 578 (1977).

[7] Y. Yamamoto, K. Yoshino, Y. Inuishi, J. Phys. Soc. Jpn. 47, 1887 (1979).

[8] A.V. Tunc, A. De Sio, D. Riedel, F. Deschler, E. Da Como, J. Parisi, E. von Hauff, Org. Electron. 13, 290 (2012)

[9] K.H. Yim, G.L. Whiting, C.E. Murphy, J.J.M. Halls, J.H. Burroughes, R.H. Friend, J.S. Kim, Adv. Mater. 20, 3319 (2008).

[10] H. Méndez, G. Heimel, A. Opitz, K. Sauer, P. Barkowski, M. Oehzelt, J. Soeda, T. Okamoto, J. Takeya, J.-B. Arlin, J.-Y. Balandier, Y. Geerts, N. Koch, I. Salzmann, Angew. Chem. 125, 1 (2013).

[11] K.S. Yook, J.Y. Lee, Adv. Mater. 26, 4218 (2014).

[12] W. Bruetting, Ch. Adachi, Physics of Organic Semiconductors, Wiley-VCH, Weinheim 2013.

[13] J. Carlé, F. Krebs, Sol. En. Mater. Sol. Cells 119 , 309 (2013).

[14] B. Lüssem, M. Riede, K. Leo, Phys. Status Solidi A 210, 9 (2013)

[15] K. Hong, S.Y. Kim, W.-K. Kim, J.-L. Lee, Electrochem. Solid-State Lett. 10, H85 (2007).

[16] C.K. Chan, F. Amy, Q. Zhang, S. Barlow, S. Marder, A. Kahn, Chem. Phys. Lett. 431, 67 (2006).

[17] H.Y. Kang, C.H. Lee, J. Korean Phys. Soc. 45, 756 (2004).

[18] Z. Ahmad, M.H. Suhail, I.I. Muhammad, W.K. AlRawi, K. Sulaiman, Q. Zafar, A.S. Hamzah, Z. Shaameri, Chin. Phys. B 22, 100701 (2013).

[19] F. Yakuphanoglu, W.A. Farooq, Acta Phys. Pol. A 119, 890 (2011).

[20] B.A. Paez-Sierra, D. Marulanda, H. Rodríguez, Proc. SPIE 9185, 918521 (2014)

[21] D. Krautz, E. Lunede, J. Puigdollers, G. Badenes, R. Alcubilla, S. Cheylan, Appl. Phys. Lett. 96 033301 (2010).

[22] A. Kumar, P.K. Bhatnagar, P.C. Mathur, K. Tada, M. Onoda, J. Mater. Sci. 40, 3849 (2005).

[23] L. Xiao-Dong, X. Zheng, Z. Fu-Jun, Z. Su-Ling, Z. Tian-Hui, G. Wei, S. Jing-Lu, K. Chao, Y. Guang, X. Xu-Rong, Chin. Phys. B 19, 118601 (2010).

[24] H. Méndez-Pinzón, D. Pardo-Pardo, J. CuéllarAlvarado, J. Salcedo-Reyes, R. Vera, B.A. PáezSierra, Univ. Scient. 15, 68 (2010).

[25] Z. Xu, H. Zang, B. Hu, Mater. Coat. 60, 49 (2008).

[27] K.-H. Choi, D.-H. Hwang, H.-M. Lee, L.-M. Do, S.D. Jung, T. Zyung, Mol. Cryst. Liq. Cryst. Sci. Technol. Sect. A Mol. Cryst. Liq. Cryst. 316, 269 (1998).

[28] J.R.H. Shaw-Stewart, T. Mattle, T.K. Lippert, M. Nagel, F.A. Nuesch, A. Wokaun, J. Appl. Phys. 113, 043104 (2013). 